\title{
Expression of human $\beta$-defensin 2 (hBD-2) in Helicobacter pylori induced gastritis: antibacterial effect of hBD-2 against Helicobacter pylori
}

Department of Molecular Pathology, Nagasaki University School of Medicine, Nagasaki, Japan

Y Hamanaka

M Nakashima

M Ito

I Sekine

Tissue and

Histopathology

Section, Division of

Scientific Data

Registry, Atomic

Bomb Disease

Institute, Nagasaki

University School of

Medicine, Nagasaki,

Japan

M Nakashima

I Sekine

Second Department of Internal Medicine,

Nagasaki University

School of Medicine,

Nagasaki, Japan

Y Hamanaka

S Kohno

Department of Bacteriology, Institute of Tropical Medicine,

Nagasaki University,

Nagasaki, Japan

A Wada

T Hirayama

Department of Medical Technology, School of Health

Sciences, Okayama

University, Okayama,

Japan

H Kurazono

Department of

Industrial Chemistry,

Tokai University,

Tokai, Japan

H Hojo

Y Nakahara

Department of Pathology, National

Nagasaki Medical

Centre, Nagasaki,

Japan

M Ito

Correspondence to: Dr M Nakashima, Tissue and Histopathology Section, Division of Scientific Data Registry, Atomic Bomb Disease Institute, Nagasaki University School of

Medicine, 1-12-4 Sakamoto,

Nagasaki 852-8523, Japan.

moemoe@net.nagasaki-u.ac.jp

Accepted for publication

26 February 2001

Y Hamanaka, M Nakashima, A Wada, M Ito, H Kurazono, H Hojo, Y Nakahara, S Kohno, T Hirayama, I Sekine

Abstract
Background-Human $\quad \beta$-defensin 2 (hBD-2) plays a role in the innate defence system at mucosal surfaces. Colonisation of Helicobacter pylori in the stomach is an important pathological factor in gastrointestinal illnesses, including gastritis, peptic ulcer, and gastric adenocarcinoma. Aims-To evaluate the antibacterial role of hBD-2 against $H$ pylori infection in the gastric mucosa.

Subjects-Biopsied gastric mucosa specimens from $H$ pylori positive $(n=6)$ and $H$ pylori negative $(\mathrm{n}=6)$ individuals were used. $H$ pylori was determined by the presence of urease activity and microscopic examination.

Methods-The specimens were examined for hBD-2 expression by reverse transcription-polymerase chain reaction (RT-PCR), immunohistochemistry, and in situ hybridisation. The antibacterial effect of hBD-2 against $H$ pylori was evaluated by the number of colony forming units of $H$ pylori after incubation with $0,10^{-9}, 10^{-8}$, $10^{-7}, 10^{-6}$, or $10^{-5} \mathrm{M}$ of $\mathrm{hBD}-2$ peptide.

Results-All six $H$ pylori positive specimens expressed a high level of hBD-2 mRNA while hBD-2 mRNA was not detected in the $H$ pylori negative specimens by RT-PCR. Immunohistochemistry using anti-hBD-2 antiserum revealed that hBD-2 was expressed in the surface epithelium of $H$ pylori infected specimens. In gastric specimens obtained after $H$ pylori eradication, hBD-2 immunoreactivity had dramatically decreased. In situ hybridisation confirmed that hBD-2 transcripts were localised in the epithelium of $H$ pylori infected gastric specimens. Incubation with hBD-2 reduced the growth rate of cultured $\mathrm{H}$ pylori in a dose dependent manner, and incubation with $10^{-5} \mathrm{M}$ hBD-2 completely inhibited the proliferation of $\boldsymbol{H}$ pylori.

Conclusions-H pylori infection induces hBD-2 expression in the human gastric epithelium. hBD-2 inhibited the growth of $H$ pylori in vitro, suggesting that $\mathrm{hBD}-2$ plays an antibacterial role in $H$ pylori induced gastritis.

(Gut 2001;49:481-487)

Keywords: human $\beta$-defensin 2; Helicobacter pylori; gastritis; antimicrobial peptide
Infection by the Gram negative, spiral shaped bacterium Helicobacter pylori has been identified as the main cause of chronic antral gastritis and duodenal ulcer. ${ }^{12}$ Colonisation of $H$ pylori in the stomach is established by neutralisation of the acidic environment with the ammonia produced by urease from the urea present in mucosal secretions. ${ }^{34}$ Although most $H$ pylori infections are asymptomatic, $H$ pylori type I, which colonises the gastric mucosa of over $50 \%$ of the world population, is associated with severe symptomatic gastritis. ${ }^{5}$ On the other hand, it has recently been suggested that $H$ pylori has beneficial effects in infected carriers who are exposed to a high level of other gastrointestinal pathogens because $H$ pylori infected individuals have a dramatically higher percentage of total $\operatorname{IgA}$ secreting cells in the antrum than non-infected subjects.

In most cases, $H$ pylori infection is associated with strong systemic antibody responses as well as mucosal antibody responses. ${ }^{7}$ The host defence response against a microorganism depends mainly on the immune system that acts through neutrophils and lymphocytes. Recently, attention has focused on antimicrobial peptides as a component of the innate immune system against microorganisms. Defensins comprise a major family of antimicrobial peptides found in mammals, and can be divided into two classes, the $\alpha$-defensins and $\beta$-defensins, according to their structural features at the genetic and protein levels. ${ }^{8}$ Some $\alpha$-defensins are stored in the azurophil granules of phagocytic leucocytes while other $\alpha$-defensins are constitutively expressed in the epithelial cells of the small intestine. ${ }^{9}$ Two types of human $\beta$-defensins were recently identified. Human $\beta$-defensin 1 (hBD-1) was isolated as a trace peptide in blood filtrates ${ }^{10}$ and is constitutively expressed in various epithelial tissues. ${ }^{11-13}$ Human $\beta$-defensin 2 (hBD-2) is a cysteine rich, low molecular weight antimicrobial peptide that was originally isolated in 1997 from psoriatic skin. ${ }^{14}$ Basal hBD-2 mRNA expression has been detected in the skin, lung,

Abbreviations used in this paper: $\mathrm{hBD}-2$, human $\beta$-defensin 2; RT-PCR, reverse transcription-polymerase chain reaction; hBD-1, human $\beta$-defensin 1 ; NSAIDs, non-steroidal anti-inflammatory drugs; Fmoc, fluorenylmethoxycarbonyl; FMP, 2-fluoro-1methylpyridinium toluene-4-sulphonate; TBS, Tris buffered saline; PBS, phosphate buffered saline; SSC, standard sodium citrate; CFU, colony forming units; $\mathrm{NF} \kappa \mathrm{B}$, nuclear transcription factor $\kappa \mathrm{B}$; IL, interleukin; PAI, pathogenicity island. 
trachea, urogenital tract, and oculus by reverse transcription-polymerase chain reaction (RTPCR). ${ }^{14}$ On proinflammatory induction, hBD-2 expression is strongly upregulated in the epithelium of the respiratory tract and skin. ${ }^{15-17}$ Thus hBD-2 is the first human $\beta$-defensin whose expression was found to be upregulated at the transcriptional level in response to contact with a microorganism ${ }^{14}$ and it plays an important role in host defence against mainly Gram negative bacteria and fungi at the mucosal surface. ${ }^{16}$ However, its expression in the epithelia of the gastrointestinal tract, and in particular the stomach, has not yet been fully clarified.

We recently demonstrated that expression of hBD-2 transcripts is induced by $H$ pylori in a human gastric cancer cell line. ${ }^{18}$ In the present study, to gain an understanding of the innate immune response to $H$ pylori, we investigated hBD-2 expression in human gastric mucosa specimens with or without $H$ pylori colonisation by RT-PCR, immunohistochemistry, and in situ hybridisation. Finally, the antibacterial effect of hBD-2 against $H$ pylori was evaluated by the number of colony forming units (CFU) of $H$ pylori after incubation with synthetic $\mathrm{hBD}-2$ peptide in vitro.

\section{Materials and methods}

RNA PREPARATION AND RT-PCR

Human gastric tissue specimens were obtained by biopsy from 12 patients who underwent gastroscopic examination. Informed consent was obtained from all patients prior to biopsy. The characteristics of the patients are summarised in table 1 . None of the patients had been treated with any non-steroidal antiinflammatory drugs (NSAIDs) or acid suppressants in the previous year at least. Gastritis activity was classified according to the Sydney system. ${ }^{19}$ The presence of $H$ pylori colonisation in each specimen was determined by the presence of urease activity, as detected by the PyloriTek test (Serim Research Corp., Elkhart, Indiana, USA) and also by microscopic examination of May-Giemsa stained specimens. RT-PCR for hBD-2 was performed on all 12 specimens. Total RNA was extracted from the tissue with Isogen (Nippon Gene, Tokyo, Japan) according to a modified guanidinephenol method, ${ }^{20}$ and quantified by measuring absorbance at $260 \mathrm{~nm}$. cDNA was synthesised from $2 \mu \mathrm{g}$ of total RNA with $2.5 \mu \mathrm{M}$ of oligo (dT) primer, $1 \mathrm{mM}$ of each deoxynucleotide

Table 1 Patient characteristics

\begin{tabular}{cllllll}
\hline Case & Sex & Age $(y)$ & Biopsy site & Urease activity & Severity of gastritis & Symptom or diagnosis \\
\hline 1 & M & 71 & Antrum & Negative & Mild & Epigastric discomfort \\
2 & F & 81 & Antrum & Negative & Normal & Epigastric discomfort \\
3 & F & 54 & Antrum & Negative & Normal & No symptom \\
4 & M & 61 & Antrum & Negative & Normal & Epigastric discomfort \\
5 & M & 73 & Antrum & Negative & Mild & Gastric cancer \\
6 & M & 87 & Body & Negative & Mild & Gastric ulcer \\
7 & F & 62 & Antrum & Positive & Severe & Chronic active gastritis \\
8 & M & 68 & Antrum & Positive & Moderate & Chronic active gastritis \\
9 & M & 58 & Antrum & Positive & Severe & Chronic active gastritis \\
10 & M & 67 & Body & Positive & Severe & Gastric cancer \\
11 & F & 72 & Body & Positive & Moderate & Chronic active gastritis \\
12 & M & 74 & Antrum & Positive & Severe & Chronic active gastritis \\
\hline \multirow{2}{*}{ According to the updated Sydney system. ${ }^{18}$} & &
\end{tabular}

${ }^{\star}$ According to the updated Sydney system. ${ }^{18}$ triphosphate, and reverse transcriptase (Life Technologies Inc, Rockville, Maryland, USA). Samples of cDNA were used for each PCR with primers for amplification of $\mathrm{hBD}-2$ (5'-ATGAGGGTCTTGTATCTCCT-3' (sense), 5'-TATCTTTGGACACCATAGTT-3' (antisense)) or human $\beta$-actin (5'TCCTCCCTGGAGAAGACTA-3' (sense), 5'-AGTACTTGCGCTCAGGAGGA-3' (antisense)) as a control. The primer pairs for both genes were chosen to amplify a region that spanned an intron in the respective genes. The hBD-2 and $\beta$-actin primers were predicted to amplify a 296 and 313 bp DNA fragment, respectively. The PCR reaction mixture contained $10 \mathrm{mM}$ Tris $\mathrm{HCl}(\mathrm{pH} 8.3), 50 \mathrm{mM} \mathrm{KCl}$, $2 \mathrm{mM} \mathrm{MgCl}_{2}, 1 \mathrm{mM}$ deoxynucleotide triphosphate, $50 \mathrm{pmol}$ of each primer, and $2.5 \mathrm{U}$ of Taq DNA polymerase (Life Technologies Inc.) in a final volume of $50 \mu \mathrm{l}$. The mixture was covered with mineral oil to prevent evaporation. The PCR conditions were 40 cycles of one minute at $94^{\circ} \mathrm{C}$, two minutes at $55^{\circ} \mathrm{C}$, and two minutes at $72^{\circ} \mathrm{C}$. PCR products were visualised on an ethidium bromide stained 1.5\% agarose gel. A sample was considered to be positive for hBD- 2 or $\beta$-actin mRNA if a band at $296 \mathrm{bp}$ or $313 \mathrm{bp}$, respectively, was visible.

SYNTHESIS OF hBD-2 PEPTIDE

The hBD-2 peptide was synthesised using the solid phase method. ${ }^{21}$ Starting with 9-fluorenylmethoxycarbonyl (Fmoc)-ProHMP resin, the peptide chain was elongated using the FastMocTM Fmoc strategy on an Applied Biosystems Model 433A peptide synthesiser (PerSeptive Biosystems, Foster City, California, USA) according to the single coupling protocol. ${ }^{22}{ }^{23}$ The protected peptide resin obtained was treated with Reagent $\mathrm{K}$ for two hours at room temperature. The crude peptide was subjected to the disulphide bond formation reaction according to a previously described method. ${ }^{17}$ The crude hBD-2 was loaded on a high performance liquid chromatography column (Cosmosil 5C18AR, 20×250 $\mathrm{mm}$; MetaChem Technologies Inc., Torrance, California, USA) using aqueous acetonitrile containing $0.1 \% \mathrm{TFA}$ as the eluent. The peak eluted at the same retention time as standard hBD-2 (Peptide Institute, Osaka, Japan), and was collected and lyophilised to give purified hBD-2. Purity was assessed by matrix assisted laser desorption ionisation-time of flight mass spectrometry (PerSeptive Biosystems) and amino acid analysis.

PREPARATION OF ANTI-hBD-2 ANTIBODY

The synthetic hBD-2 peptide was coupled to keyhole limpet haemocyanin. ${ }^{24}$ Rabbits were immunised subcutaneously with the antigen. Titration of anti-hBD-2 antibody was carried out according to the Ouchterlony double gel diffusion test. ${ }^{25}$ Antibodies were purified from antisera by affinity chromatography on immobilised synthetic peptides. ${ }^{26}$ Purified synthetic peptides $(1.0 \mathrm{mg})$ were coupled to the column packed with 2-fluoro-1-methylpyridinium toluene-4-sulphonate (FMP)-cellurofine (Seikagaku Kougyo Co., Tokyo, Japan). After 
washing the column with Tris buffered saline (TBS), the antiserum in an appropriate volume $(10 \mathrm{ml})$ was added to the peptide conjugated FMP-cellurofine column and incubated for one hour at room temperature. After washing the column with TBS supplemented by $1 \%$ Triton X-100, the antibodies were eluted with $0.1 \mathrm{M}$ glycine $\mathrm{HCl}, \mathrm{pH} 2.5$, and collected in a tube containing 0.05 volume of $1 \mathrm{M}$ Tris solution. Eluted fractions were dialysed against phosphate buffered saline (PBS) and used as anti-hBD-2 antibody in the immunohistochemical analysis. The hBD-2 specific antibody did not cross react with hBD-1 when tested against the recombinant peptides by western blotting.

IMMUNOHISTOCHEMISTRY

To demonstrate the distribution of hBD-2 expression in gastric tissue, immunohistochemical analysis was performed on $10 \%$ buffered, formalin fixed, paraffin embedded samples of gastric specimens from the 12 patients described above, using the ABC-Peroxidase kit (Vector Laboratories, Inc., Burlingame, California, USA). Three patients with $H$ pylori positive gastritis (case Nos 7, 8, and 9 in table 1) were treated with antibiotics $(20 \mathrm{mg} /$ day sodium rabeprazole, $600 \mathrm{mg} /$ day clarithromycin, and $1500 \mathrm{mg} /$ day amoxicillin) for five days perorally to eradicate $H$ pylori, and then re-biopsied on the 28th day after completion of treatment. The presence of $H$ pylori after antibiotic treatment was evaluated by both microscopic examination and the urease test. Samples for immunohistochemical analysis were cut into $4 \mu \mathrm{m}$ sections, deparaffinised in xylene, and rehydrated in PBS. The deparaffinised sections were immersed in $0.3 \%$ hydrogen peroxide in methanol to block the internal peroxidase, preincubated with $1 \%$ normal bovine serum to prevent non-specific binding, and then incubated overnight at $4^{\circ} \mathrm{C}$ with 100 -fold diluted anti-hBD-2 antibody. After washing in PBS, the slides were incubated for 30 minutes with biotinylated anti-mouse IgG and then with peroxidase conjugated avidin. The reaction products were resolved using diaminobenzidine. The specimens were counterstained with haematoxylin. Negative controls were prepared in each case by replacing the primary antibody with non-immunised rabbit serum, and did not show any staining (data not shown).

\section{IN SITU HYBRIDISATION}

Biopsied $4 \%$ paraformaldehyde fixed, frozen samples were sectioned at $10 \mu \mathrm{m}$. Digoxigenin labelled hBD-2 RNA probes were prepared by subcloning the full length hBD-2 cDNA into the SmaI site of pBluescript KS (+) (Promega, Madison, Wisconsin, USA), and the resultant vector was used as a template for the riboprobe. The open reading frame of hBD-2 cDNA shows $39 \%$ identity with hBD-1. The antisense probe was generated using the EcoRI digested linearised template and T7 RNA polymerase. Similarly, the sense probe was prepared for negative control experiments using the BamHI digested template and T3 RNA polymerase.
The fixed sections were digested by placing them in $10 \mu \mathrm{g} / \mathrm{ml}$ proteinase $\mathrm{K}$ in TE ( $\mathrm{pH}$ 8.0) at $37^{\circ} \mathrm{C}$ for 30 minutes, followed by postfixation in $4 \%$ paraformaldehyde. The slides were immersed in $0.2 \mathrm{~N} \mathrm{HCl}$ for 10 minutes and were subsequently acetylated for 10 minutes in freshly prepared $0.25 \%$ acetic anhydride in 0.1 $M$ triethanolamine ( $\mathrm{pH} \mathrm{8.0)}$. After prehybridisation in $4 \times$ standard sodium citrate (SSC)/ $50 \%$ deionised formamide for one hour at $37^{\circ} \mathrm{C}$, the slides were hybridised in a solution of $200 \mathrm{ng} / \mathrm{ml}$ antisense or sense probe in $50 \%$ deionised formamide, $10 \mathrm{mM}$ Tris $\mathrm{HCl}(\mathrm{pH}$ 7.6), $1 \mathrm{mM}$ EDTA (pH 8.0), $300 \mathrm{mM} \mathrm{NaCl}$, $0.25 \%$ sodium dodecyl sulphate, $1 \times$ Denhardt's solution, $10 \%$ dextran sulphate, and $200 \mu \mathrm{m} / \mathrm{ml}$ yeast tRNA at $42^{\circ} \mathrm{C}$ for 16 hours. After hybridisation, the specimens were rinsed in $2 \times \mathrm{SSC}$ for 30 minutes at $37^{\circ} \mathrm{C}$ and digested with $20 \mu \mathrm{g} / \mathrm{ml}$ of RNaseA at $37^{\circ} \mathrm{C}$ for $30 \mathrm{~min}-$ utes. After washing once with $1 \times \mathrm{SSC}$ at $37^{\circ} \mathrm{C}$ for one hour and twice with $0.1 \times \mathrm{SSC}$ at $37^{\circ} \mathrm{C}$ for 30 minutes each, the sections were subjected to immunohistochemical analysis for detection of the hybridised probes using an alkaline phosphatase conjugated antidigoxigenin antibody (Boehringer Mannheim, Indianapolis, Indiana, USA). The alkaline phosphatase reaction was visualised with 5-bromo4-chloro-3-indolyl phosphate and nitroblue tetrazolium chloride.

ANTIMICROBIAL ASSAY

The toxin producing strain of $H$ pylori, ATCC49503 (tox ${ }^{+}$strain 60190), was used in this assay. $H$ pylori was recovered from frozen stocks by seeding on a blood agar plate (Mueller Hinton II agar with $7 \%$ horse blood) at $37^{\circ} \mathrm{C}$ for three days under microaerophilic conditions $\left(10 \% \mathrm{O}_{2}\right.$ and $\left.10 \% \mathrm{CO}_{2}\right)$ generated with Anaeropack Campylo (Mitsubishi Gas Chemicals Corp., Tokyo, Japan). Bacteria harvested from the plates using cotton swabs were suspended in $200 \mathrm{ml}$ of brain heart infusion broth containing $10 \%$ fetal calf serum and then grown in liquid culture at $37^{\circ} \mathrm{C}$ for three days with vigorous shaking in a controlled microaerophilic atmosphere. Mixtures containing $2.4 \times 10^{4} \mathrm{CFU}$ of $\mathrm{H}$ pylori and synthetic hBD-2 peptide at concentrations of $0,10^{-9}, 10^{-8}, 10^{-7}$, $10^{-6}$, or $10^{-5} \mathrm{M}$ in $100 \mu \mathrm{l}$ of $10 \mathrm{mM}$ phosphate buffer ( $\mathrm{pH} 7.4$ ) with $50 \mathrm{mM} \mathrm{NaCl}$ were incubated at $37^{\circ} \mathrm{C}$ for 20 minutes. The $H$ pylori cells from each preparation were plated on a blood agar plate and incubated at $37^{\circ} \mathrm{C}$ for three days under microaerophilic conditions. The number of CFU was counted. This antimicrobial assay is performed under hypotonic (hypo-osmolal) conditions because the antimicrobial function of hBD-2 is highly salt sensitive and almost completely inhibited by more than $150 \mathrm{mM}$ of $\mathrm{NaCl}^{27}{ }^{28}$

\section{Results}

RT-PCR

To evaluate the effect of $H$ pylori colonisation in gastric tissue on hBD-2 mRNA expression, gastric specimens from six $H$ pylori positive and six $H$ pylori negative patients, as determined by the urease test and microscopic examination, 


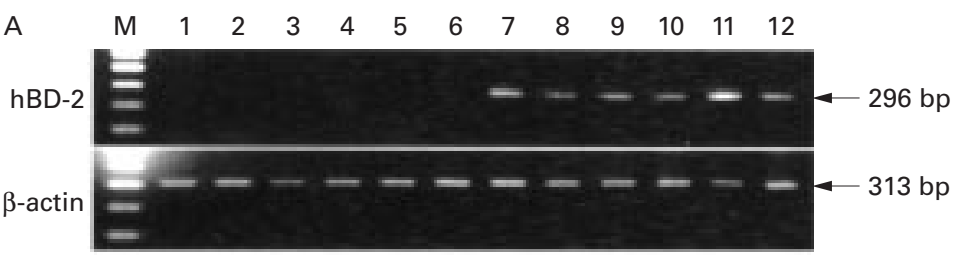

B

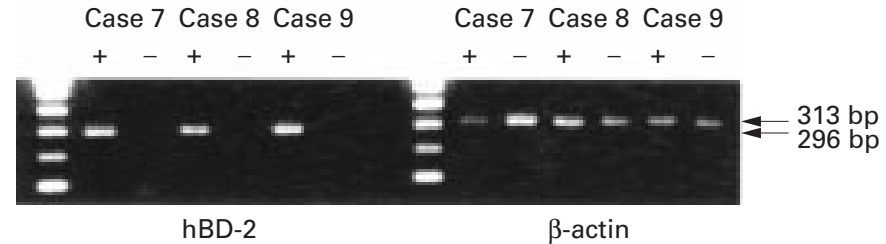

Figure 1 Reverse transcription-polymerase chain reaction (RT-PCR) analysis of human $\beta$-defensin $2(h B D-2)$ expression in gastric mucosa specimens. (A) Lanes 1-12 correspond to gastric specimens obtained from cases 1-12, respectively, in table 1. Cases 1-6 were not infected with Helicobacter pylori and cases 7-12 were infected with H pylori. (B) Expression of hBD-2 mRNA in gastric mucosa specimens obtained from cases 7-9 before and after $H$ pylori eradication. Cases 7-9 in table 1 were applicable in this experiment. + , before $H$ pylori eradication; -, after H pylori eradication; $M, 100 \mathrm{bp} D N A$ ladder as a marker.
IMMUNOHISTOCHEMISTRY

We performed immunostaining for hBD-2 with a newly developed polyclonal antibody. hBD-2 expression was detected in the gastric specimens from the six $H$ pylori positive patients but not in the specimens from the six $H$ pylori negative patients (fig 2 ). In the $H$ pylori positive gastric mucosa specimens, hBD-2 immunoreactivity was restricted to the surface epithelium and gastric pits and was not detected in the lamina propria, inflammatory cells, or other gastric glands. The gastric mucosa specimens obtained after treatment with antibiotics for eradication of $H$ pylori $(\mathrm{n}=3)$ were also examined. $H$ pylori were not detected in the gastric mucosa specimens obtained after antibiotic treatment, by both the urease test and microscopic examination. hBD-2 immunoreactivity had dramatically decreased in the gastric mucosa specimens obtained after antibiotic treatment (fig 3).

IN SITU HYBRIDISATION

To confirm localisation of hBD-2 expression in $H$ pylori infected gastric mucosae at the transcriptional level, we performed in situ hybridisation with hBD-2 riboprobes on frozen sections of the gastric mucosa specimens from cases 1 and 2 in the $H$ pylori negative group and cases 11 and 12 in the $H$ pylori positive group. Using the hBD-2 antisense probe, a positive signal for hBD-2 mRNA was detected in the surface epithelium of the gastric mucosa specimens obtained from the $H$ pylori positive cases. No signal was evident in any of the specimens using the sense probe as a control study (fig 4). As another control experiment, RNaseA treatment of the gastric mucosa specimens from $H$
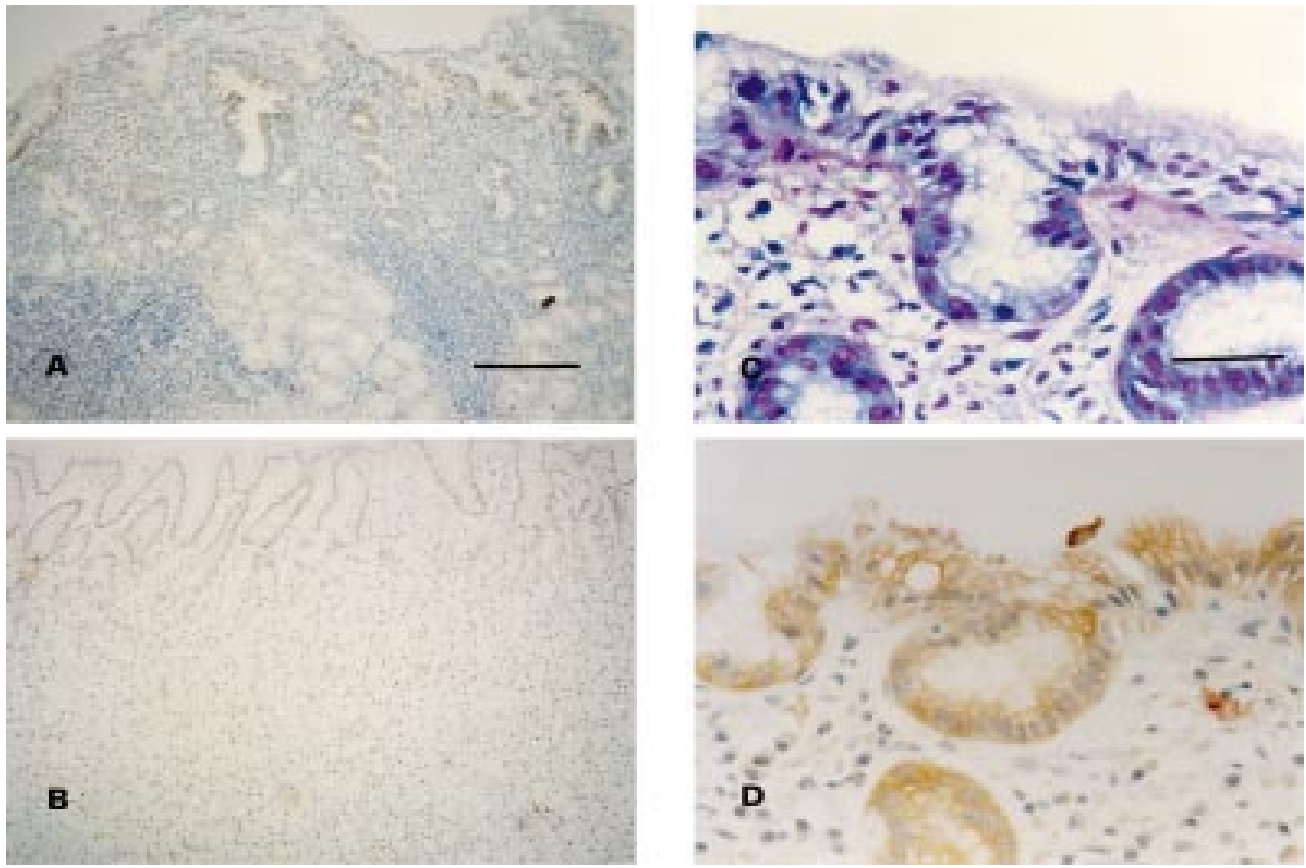

Figure 2 Immunohistochemical analysis of human $\beta$-defensin $2(h B D-2)$ expression in gastric mucosa specimens with (case 9) (A) or without (case 3) (B) Helicobacter pylori colonisation. Both (A) and (B) have the same magnification. The scale bar in (A) represents $200 \mu \mathrm{m}$. (C) May-Giemsa stained section adjacent to (D) and demonstrating colonisation of $H$ pylori at the mucosal surface (case 9). (D) Immunoreactivity for hBD-2 in gastric epithelium at a high magnification can be seen. The scale bar in (C) represents $800 \mu \mathrm{m}$. 

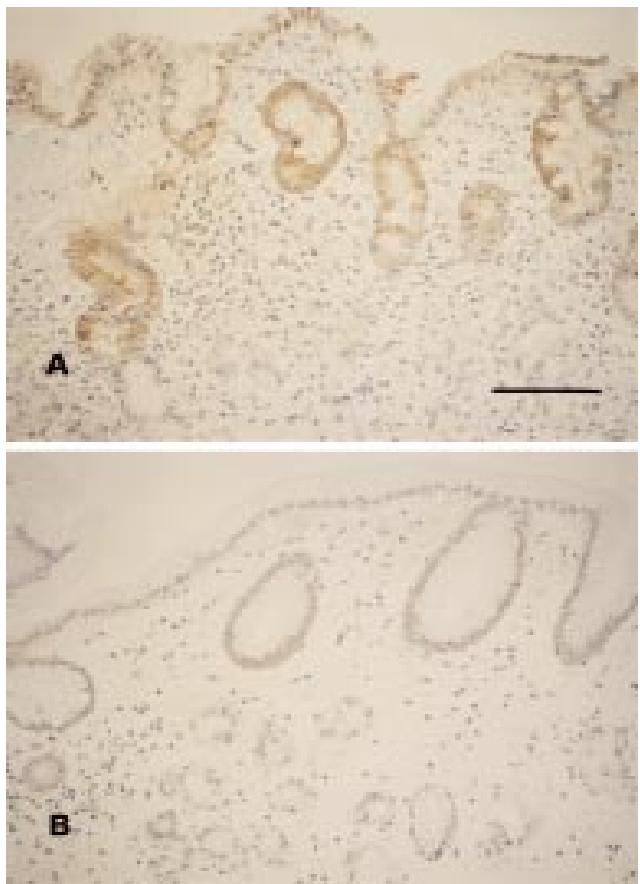

Figure 3 Immunohistochemical analysis of human $\beta$-defensin $2(h B D-2)$ expression in gastric mucosa specimens obtained before (A) and after (B) Helicobacter pylori eradication in case No 7. (A) and (B) have the same magnification. The scale bar in $(A)$ represents $200 \mu \mathrm{m}$.

pylor infected individuals completely abolished the positive signal for hBD-2 mRNA (data not shown).
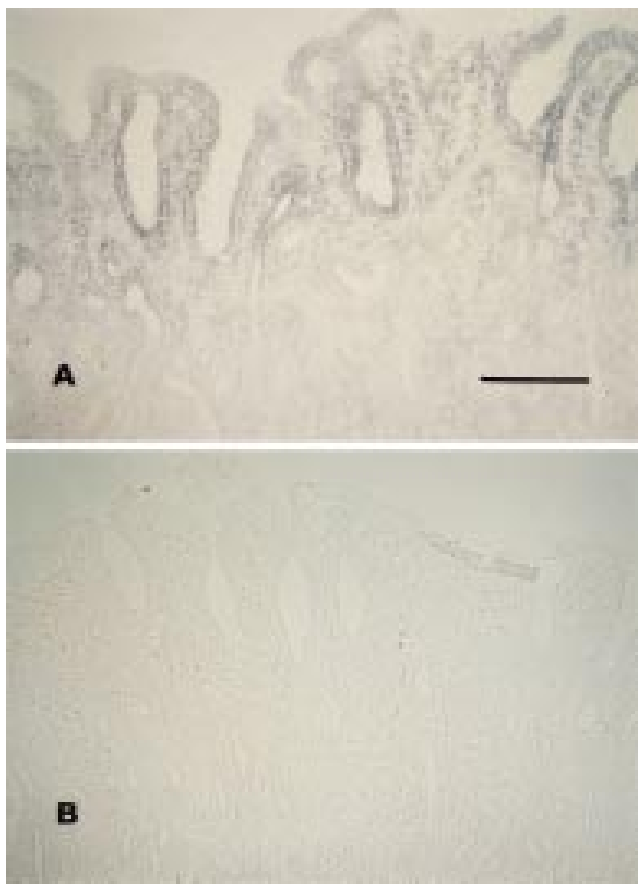

Figure 4 In situ hybridisation of human $\beta$-defensin 2 $(h B D-2) m R N A$ in Helicobacter pylori infected gastric mucosa specimens. (A) A hybridisation signal with the $h B D-2$ antisense probe was predominantly observed in the surface epithelium and pits, and also in the inflammatory cells scattered in the interstitium (case 12). The full length hBD-2 antisense probe may cross react with $h B D-1$ as a leucocytic defensin because the open frame of $h B D-2 c D N A$ shows $39 \%$ identity with $h B D-1 .{ }^{34}$ (B) No signals were detected on hybridisation with the $h B D-2$ sense probe as a negative control (case 12). (A) and (B) have the same magnification. The scale bar in $(A)$ represents $100 \mu \mathrm{m}$.

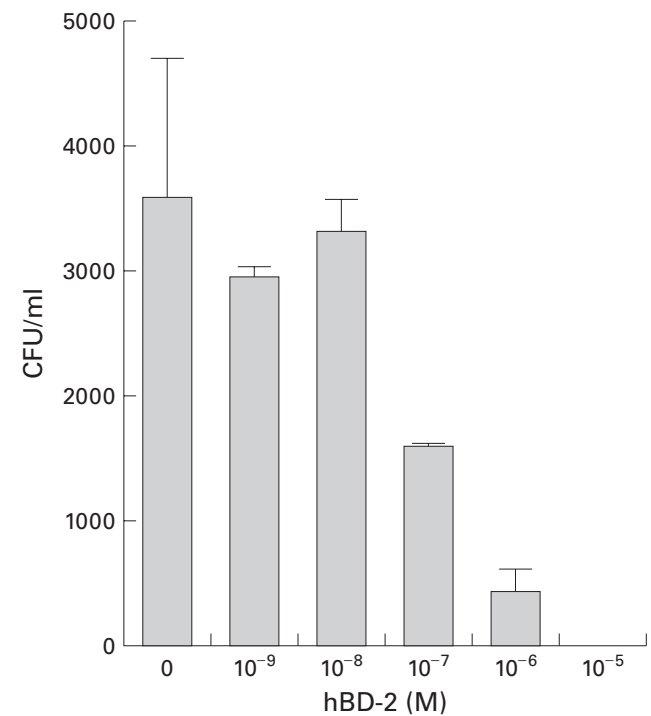

Figure 5 Antimicrobial effect of synthetic human $\beta$-defensin $2(h B D-2)$ peptides on Helicobacter pylori colony formation in an in vitro assay. Each bar represents mean (SEM). CFU, colony forming units.

ANTIMICROBIAL ASSAY

To determine whether hBD-2 has an antibacterial effect on $H$ pylori, $H$ pylori were incubated in solutions containing various concentrations of synthetic hBD-2 peptide for 20 minutes and then plated for three days. The number of CFU of $H$ pylori was counted. As shown in fig 5, in $H$ pylori that had been pretreated with higher concentrations of synthetic hBD-2, the number of CFU decreased in a dose dependent manner. The number of CFU of $H$ pylori on preincubation with hBD-2 at concentrations of $0,10^{-9}, 10^{-8}, 10^{-7}, 10^{-6}$, or $10^{-5} \mathrm{M}$ was 3567 (1129), 2933 (88), 3300 (265), 1567 (33), 433 (167), and $0(0)$, respectively. Thus the growth rate of $H$ pylori was suppressed by $50 \%$ on preincubation with $10^{-7} \mathrm{M}(0.3 \mu \mathrm{g} / \mathrm{ml}) \mathrm{hBD}-2$ peptide, and was completely inhibited on preincubation with $10^{-5} \mathrm{M}(30 \mu \mathrm{g} / \mathrm{ml})$ of hBD-2 peptide.

\section{Discussion}

Although a low level of hBD-2 mRNA is present in healthy epithelia, its expression is greatly upregulated by inflammatory stimuli. ${ }^{14}$ The present study revealed that the gastric tissue of patients with $H$ pylori infected gastritis overexpressed hBD-2. The gastric specimens from all six $H$ pylori positive cases overexpressed hBD-2 mRNA, as assessed by RT-PCR, while those from six $H$ pylori negative cases showed only faint hBD-2 expression, suggesting that $H$ pylori colonisation induces hBD-2 expression in the gastric mucosa. In our recent report, we demonstrated that the cag pathogenicity island (PAI) of $H$ pylori is important for inducing hBD-2 mRNA expression in the MKN45 gastric carcinoma cell line. ${ }^{18}$ The 5 ' flanking region of the hBD-2 gene contains consensus binding sequences for nuclear transcription factor $\kappa \mathrm{B}(\mathrm{NF} \kappa \mathrm{B}) .{ }^{29}$ Since cag PAI is essential for $H$ pylori mediated interleukin (IL) $-8^{3031}$ and intercellular adhesion molecule $1^{32}$ secretion and these require activation of 
$\mathrm{NF} \kappa \mathrm{B},{ }^{33}{ }^{34} H$ pylori mediated hBD-2 mRNA induction should also involve direct or indirect activation of $\mathrm{NF} \kappa \mathrm{B}$. Further studies are needed to evaluate this hypothesis.

hBD-2 is specifically produced by human epithelial cells ${ }^{1427}$ but not fibroblasts, ${ }^{16}$ and the presence of hBD-2 may have an antimicrobial effect on organ surfaces that are continuously exposed to various microorganisms. The defence mechanism via hBD-2 is completely independent of the leucocyte dependent immune defence mechanisms. ${ }^{16}$ Immunohistochemistry revealed that $\mathrm{hBD}-2$ is localised in the $H$ pylor $i$ infected gastric surface epithelium and gastric pits but not in other gastric glands, inflammatory cells, nor in the lamina propria. That hBD-2 is expressed in the epithelium of the stomach with $H$ pylori colonisation was confirmed by in situ hybridisation at the transcriptional level. These findings suggest that exposure to $H$ pylori upregulates hBD-2 expression in the gastric surface epithelium. We have recently demonstrated that hBD-2 mRNA is inducibly expressed in MKN45 cells after incubation with $H$ pylori while hBD-2 expression is not detected in cells exposed to a culture medium after filtering off $H$ pylori. ${ }^{18}$ Interestingly, hBD-2 immunoreactivity had dramatically decreased in gastric mucosa specimens obtained 28 days after completion of antibiotic treatment. Furthermore, the level of hBD-2 transcripts in the $H$ pylori eradicated gastric mucosa specimens had decreased to an undetectable level by RT-PCR. These findings support the importance of direct contact of $H$ pylori with the surface epithelium for inducing hBD-2 expression in the host tissue. Furthermore, it is established that proinflammatory cytokines such as tumour necrosis factor $\alpha$ and IL-1 $\beta$, which are known to be involved in $H$ pylori induced gastritis, ${ }^{35}$ have been found to upregulate hBD-2 mRNA expression in a dose dependent manner. ${ }^{36}$ Thus hBD-2 may be an inducible antimicrobial factor produced by gastric mucosa either on contact with $H$ pylori or by endogenously released proinflammatory cytokines.

The presence of hBD-2 elicits antimicrobial activity on host organ surfaces. ${ }^{14}$ To evaluate the effect of gastric hBD-2 on the growth of $H$ pylori, we performed an in vitro antimicrobial assay with synthetic hBD-2. It is well known that hBD-2 activity is highly salt sensitive. Indeed, the ability of hBD-2 to inhibit growth of Escherichia coli diminished eightfold when the salt concentration was increased from 20 to $150 \mathrm{mM} .^{28}$ Therefore, this assay was performed under a hypotonic environment containing 50 $\mathrm{mM} \mathrm{NaCl}$. In our experiment, the growth rate of cultured $H$ pylori decreased on synthetic hBD-2 pretreatment in a dose dependent manner, and growth was completely inhibited on preincubation with $10^{-5} \mathrm{M}(30 \mu \mathrm{g} / \mathrm{ml})$ synthetic hBD-2. It has been reported that the LD90 values of natural hBD-2 preparations against $E$ coli, Pseudomonas aeruginosa, and Candida albicans are 10, 10, and $25 \mu \mathrm{g} / \mathrm{ml}$, respectively. ${ }^{16}$ Thus hBD-2 seems to have antimicrobial activity against $H$ pylori as well as other Gram negative bacteria and fungi, suggesting that loss of hBD-2 induction in the stomach may exacerbate $H$ pylori induced gastritis. Although colonisation of the human stomach by $H$ pylori is a predisposing factor for gastrointestinal illnesses, ${ }^{37}$ it has recently been demonstrated that $H$ pylori may actually have beneficial effects on infected carriers who are heavily exposed to other gastrointestinal pathogens. ${ }^{38}$ The gastric hBD-2 induced by $H$ pylori infection may also play a role in protection from other pathogens.

In conclusion, we demonstrated overexpression of hBD-2 mRNA in all of the biopsied gastric mucosa specimens with $H$ pylori colonisation. Immunohistochemistry and in situ hybridisation revealed that in $H$ pylori infected gastric mucosa specimens, hBD-2 is specifically expressed in the gastric surface epithelium and pits. The synthetic hBD-2 peptide showed an antimicrobial effect against $H$ pylori in vitro. Since a high level of hBD-2 is expressed in the gastric mucosa of patients with severe active gastritis, hBD-2 may be involved in the pathophysiology of $H$ pylori induced gastritis.

The authors are grateful to Mr Kawata for his technical assistance in preparing the figures in this paper.

1 Blaser MJ. Hypotheses on the pathogenesis and natural history of Helicobacter pylori-induced inflammation. Gastroenterology 1992;102:720-7.

2 Marshall BJ, Warren JR. Unidentified curved bacilli in the stomach of patients with gastritis and peptic ulceration. Lancet 1984;1:1311-15.

3 Dunn BE, Cambell GP, Perez-Perez GI, et al. Purification and characterization of urease from Helicobacter pylori. $\mathcal{F}$ Biol Chem 1990;265:9464-9.

4 Eaton KA, Brooks CL, Morgan DR, et al. Essential role of urease in pathogenesis of gastritis induced by Helicobacter pylori in gnotobiotic piglets. Infect Imтип 1991;59:2470-5.

5 Nagata H, Wada A, Kurazono H, et al. Application of beadELISA method to detect Helicobacter pylori VacA. Microb Pathog 1999;26:103-10.

6 Mattson A, Lönroth H, Qiuding-Järbrink M, et al. Induction of $\mathrm{B}$ cell responses in the stomach of Helicobacter pylori-infected subjects after oral cholera vaccination. $\mathcal{F}$ Clin pylori-infected subjects
Invest $1998 ; 102: 51-6$.

7 Wyatt JI, Rathbone BJ. Immune response of the gastric mucosa to Campylobacter pylori. Scand f Gastroenterol Suppl 1988;142:44-9.

8 Diamond G, Bevins CL. Beta-defensins: Endogenous antibiotics of the innate host defense response. Clin Immun Immunopathol 1998;88:221-5.

9 Bevins CL, Martin-Porter E, Ganz T. Defensins and innate host defence of the gastrointestinal tract. Gut 1999;45:91115.

10 Bensch EW, Raida M, Magert HJ, et al. hBD-1: A novel beta-defensin from human plasma. FEBS lett 1995;368: 331-5.

11 Valore EV, Park $\mathrm{CH}$, Quayle AJ, et al. Human betadefensin-1: An antimicrobial peptide of urogenital tissues. $\mathcal{F}$ Clin Invest 1998;101:1633-42.

12 Schnapp D, Reid CJ, Harris A. Localization of expression of human beta-defensin-1 in the pancreas and kidney. F Pathol 1998;186:99-103.

13 Tarver AP, Clark DP, Diamond G, et al. Enteric betadefensin: molecular cloning and characterization of a gene with inducible intestinal epithelial cell expression associwith inducible intestinal epithelial cell expression associ-
ated with cryptosporidium parvum infection. Infect Immun ated with cryptosp
$1998 ; 66: 1045-56$.

14 Harder J, Bartels J, Christophers E, et al. A peptide antibiotic from human skin. Nature 1997;387:861.

15 McNamara NA, Van R, Tuchin OS, et al. Ocular surface epithellia express mRNA for human beta-defensin-2. Exp Eye Res 1999; 69:483-90.

16 Schröder J-M, Harder J. Molecules in focus human beta-defensin-2. Int $\mathcal{F}$ Biochem Cell B 1999;31:645-51.

17 Hiratsuka T, Nakazato $M$, Date Y, et al. Identification of human beta-defensin-2 in respiratory tract and plasma and its increase in bacterial pneumonia. Biochem Biophys Res Commun 1998;249:943-7.

18 Wada A, Mori N, Oishi K, et al. Induction of human beta-defensin-2 mRNA expression by Helicobacter pylori in heta-defensin-2 mRNA expression by Helicobacter pylori in
human gastric cell line MKN45 cells on cag pathogenicity
island. Biochem Biophys Res Commun 1999;263:770-4.

19 Dixon MF, Genta RM, Yardley JH, et al. Classification and grading of gastritis. The updated Sydney System. International Workshop on the Histopathology of Gastritis, Houston 1994. Am F Surg Pathol 1996;20:1161-81. 
20 Chomczynski P, Sacchi N. Single-step method of RNA isolation by acid guanidinium thiocyanate-phenol-chloroform extraction. Anal Biochem 1987;162:156-9.

21 Ainpour PR, Wickstrom E. Modifications of solid phase peptide synthesis to obtain homogeneous oligoprolines in high yield. Int f Pept Protein Res 1980;15:225-35.

22 Ball HL, Mascagni P. Chemical synthesis and purification of proteins: a methodology. Int $\mathcal{F}$ Pept Protein Res 1996;48:3147.

23 King DS, Fields CG, Fields GB. A cleavage method which minimizes side reactions following Fmoc solid phase peptide synthesis. Int 7 Pept Protein Res 1990;36:255-66.

24 Liu FT, Zinnecker M, Hamaoka T, et al. New procedures for preparation and isolation of conjugates of proteins and a synthetic copolymer of D-amino acids and immunochemical characterization of such conjugates. Biochemistry 1979; 18:690-3.

25 Ouchterlony O. Antigen-antibody reactions in gels. Acta Pathol Microbiol Scand 1949;26:507-15.

26 Imajoh-Ohmis, Tokit K, Ochiait, et al. Topology of cytochrome 6558 . chrome 6558 in neutrophil membrane analyzed by anti-peptide antibodies and proteolysis. F Biol Chem 1992 267:180-4

27 Singh PK, Jia HP, Wiles K, et al. Production of beta-defensins by human airway epithelia. Proc Natl Acad Sci USA 1998;95:14961-6.

28 Bals R, Wang X, Wu Z, et al. Human beta-defensin 2 is a salt-sensitive peptide antibiotic expressed in human lung. $\mathcal{F}$ Clin Invest 1998;102:874-80.

29 Liu L, Wang L, Jia HP. Structure and mapping of the human beta-defensin HBD-2 gene and its expression at sites of inflammation. Gene 1998;222:237-44.
30 Tummuru MKR, Sharma SA, Blaser MJ. Helicobacter pylori picB, a homologue of the Bordetella pertussis toxin secretion protein, is required for induction of $\mathrm{IL}-8$ in gastric epithelial cells. Mol Microb 1995;18:867-76.

31 Censini S, Lange C, Xiang Z, et al. cag, a pathogenicity island of Helicobacter pylori, encodes type I-specific and disease-associated virulence factors. Proc Natl Acad Sci USA 1996;93:14648-53.

32 Mori N, Wada A, Hirayama T, et al. Activation of intercelluar adhesion molecule 1 expression by Helicobacter pylor $i$ is lar Infect Immun 2000;68:1806-14.

33 Aihara $M$, Tsuchimoto D, Takizawa $\mathrm{H}$, et al. Mechanisms involved in Helicobacter pylori-induced interleukin-8 production by a gastric cancer cell line, MKN45. Infect Immun 1997;65:3218-24

34 Munzenmainer A, Lange C, Glocker E, et al. A secreted/ shed product of Helicobacter pylori activates transcription factor nuclear factor-kappa B. F Immunol 1997;159:61407.

35 Lindholm C, Quiding-Järbrink M, Lönroth $\mathrm{H}$, et al. Local cytokine response in Helicobacter pylori-infected subjects. Infect Immun 1998;66:5964-71.

36 Harder J, Meyer-Hoffert U, Teran LM, et al. Mucoid Pseudomonas aeruginosa, TNF- $\alpha$, and IL-1 $\beta$, but not IL-6, induce human $\beta$-defensin-2 in respiratory epithelia. $A m \mathcal{F}$ Respir Cell Mol Biol 2000;22:714-21.

37 Blaser MJ. Helicobacter pylori and gastric diseases. BMF 1998;316:1507-10.

38 Pütsep K, Brändén C-I, Boman HG, et al. Antibacterial peptide from $H$. pylori. Nature 1999;398:671-2.

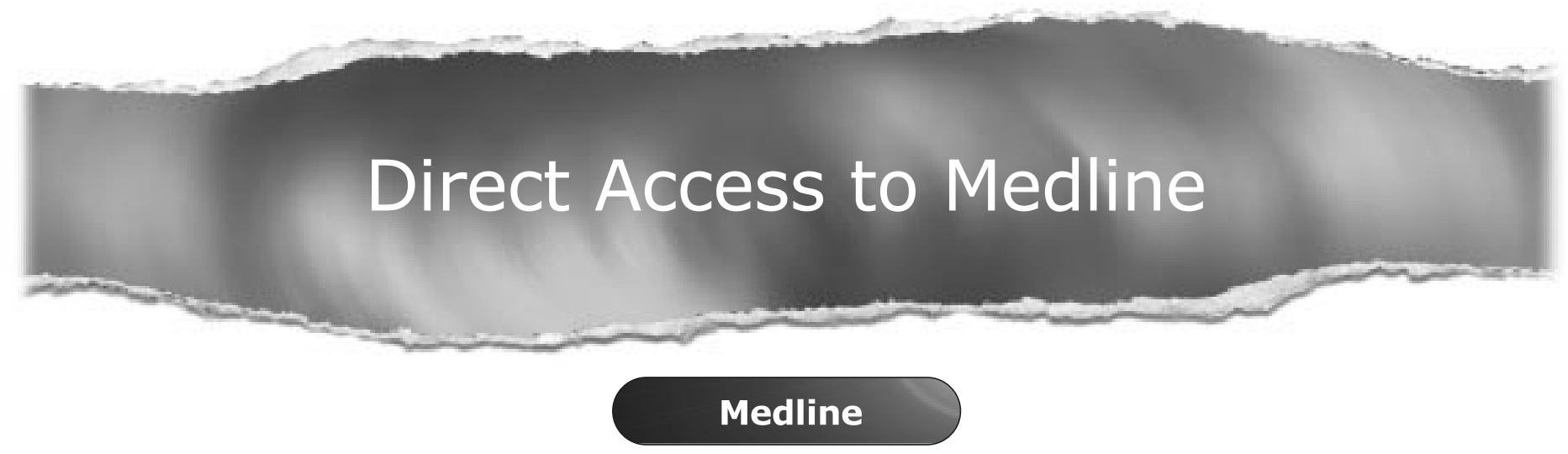

Link to Medline from the homepage and get straight into the National Library of Medicine's premier bibliographic database. Medline allows you to search across 9 million records of bibliographic citations and author abstracts from approximately 3,900 current biomedical journals.

\section{www.gutjnl.com}

